Jörg Kilian, Thomas Niehr, Jürgen Schiewe Sprachkritik 


\section{Germanistische Arbeitshefte}

Herausgegeben von

Thomas Gloning und Jörg Kilian

\section{Band 43}




\section{Jörg Kilian, Thomas Niehr, Jürgen Schiewe}

Sprachkritik

Ansätze und Methoden der kritischen Sprachbetrachtung

2., überarbeitete und aktualisierte Auflage

\section{DE GRUYTER}


ISBN 978-3-11-040181-3

e-ISBN (PDF) 978-3-11-040966-6

e-ISBN (EPUB) 978-3-11-042363-1

ISSN 0344-6697

\section{Library of Congress Cataloging-in-Publication Data}

A CIP catalog record for this book has been applied for at the Library of Congress.

\section{Bibliografische Information der Deutschen Nationalbibliothek}

Die Deutsche Nationalbibliothek verzeichnet diese Publikation in der Deutschen Nationalbibliografie; detaillierte bibliografische Daten sind im Internet über http://dnb.dnb.de abrufbar.

(C) 2016 Walter de Gruyter GmbH, Berlin/Boston Druck und Bindung: CPI books GmbH, Leck

@ Gedruckt auf säurefreiem Papier

Printed in Germany

www.degruyter.com 